\title{
OPTIMAL PLANNING WITH WIND ENERGY FOR A NEW CITY IN EGYPT
}

\author{
A. A. Abou El-Ela*, S. M. Allam* and H. R. Somat** \\ *Electrical Engineering Dept., Faculty of Engineering, Minoufiya University, Shebin El-Kom, Egypt \\ **Operation engineer, Egyptian Electricity Transmission Company, Egypt
}

\begin{abstract}
This paper presents the load forecasting of a new city using the conventional techniques such as extrapolation of trend curves and modern techniques of load forecasting such as Genetic Algorithm (GA) and Particle Swarm Optimization (PSO) technique. A comparison between different wind generator modes (WGMs) as related to the technical and economical sides is presented. The optimal WGM is chosen for designing the wind farm at the Borg El-Arab site which has a new city in Egypt.
\end{abstract}

Keywords : Long-Term Load Forecasting, Genetic Algorithm (GA), Particle Swarm Optimization (PSO) technique, Wind Farm Design.

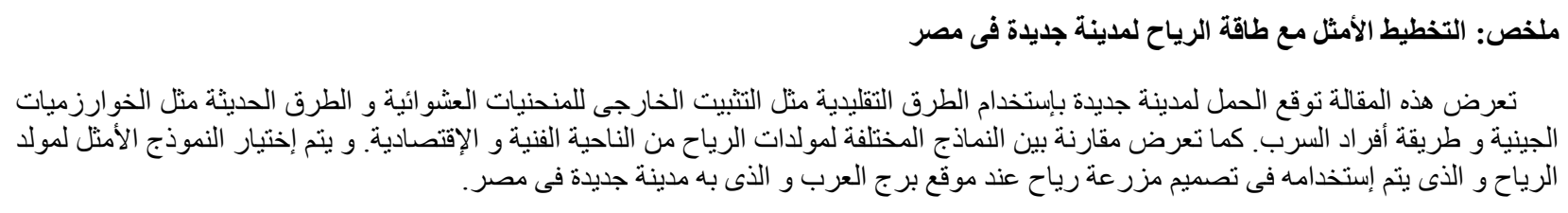

\section{Introduction}

In order to feed any new city with energy requirements, it is necessary to determine the amount and source of the energy required for this city. Also, it is necessary to determine the method of usage of this source to generate the required energy. The amount of the required energy can be determined by using long-term load forecasting for the new city peak load demand during different stages of constructing the new city. The electrical load forecasting forms the basis of power system planning and provides information on expected consumption increase [1]. Many research results have been published for applying the conventional and modern load forecasting techniques. Modern load forecasting techniques, such as GA, Artificial Neural Networks (ANN), PSO technique, fuzzy logic ... etc., have been developed recently, showing encouraging results. They have the ability to handle the nonlinear relationships between load and the factors affecting it directly from historical data [2].

After determining the future load demand of the new city, it is required to determine the required energy source if it will be generated from conventional or renewable energy sources. Wind energy is one of Renewable Energy Sources (RESs) which is converted to a useful form of energy, such as using: wind turbines to make electricity, windmills for mechanical energy, wind pumps for water

pumping or drainage, or sails to propel ships. Wind power, as an alternative to fossil fuels, is plentiful, renewable, widely distributed, clean produces no greenhouse gas emissions during operation and uses little land [3,4]. As mentioned before that the wind energy is one of RESs which is converted to a useful form of energy, such as using wind turbines to make electricity.

This paper presents the load forecasting of the new Borg El-Arab city during different stages of constructing of it, which is a part of Alexandria city in Egypt. Extrapolation of trend curves as conventional technique and GA and PSO technique as modern techniques of long-term load forecasting are used for this purpose. A wind farm at the installation site of the new city to be integrated with conventional power supply is constructed to feed its load.

\section{Problem formulation}

In this thesis, two problems can be formulated to achieve the thesis objectives as follows:

\subsection{Long-Term Load Forecasting}

The forecasted peak load demand can be represented by many simple approximations, which are: linear, exponential and logarithmic equations ... etc. In these approximations the future load is 
predicted using the available past historical data [5, 6]. In this paper, linear and exponential approximations are used as given in the following equations, respectively [5 - 7]:

$P_{D i}=a+b X_{i}$

$P_{D i}=e^{a+b X_{i}}$

$X_{i}=x_{i}-x_{o}$

Where, $\mathrm{P}_{\mathrm{Di}}$ is the forecasted load demand. $(\mathrm{a}, \mathrm{b})$ are the coefficients and exponents of the given functions. $\mathrm{x}_{\mathrm{i}}$ is the ith year in which the peak load $\mathrm{P}_{\mathrm{Di}}$ is considered. $x_{0}$ is the base year.

\subsubsection{Long-term load forecasting using conventional technique}

Extrapolation of trend curves technique is used as a conventional technique and the coefficients and exponents $(\mathrm{a}, \mathrm{b})$ can be obtained by using the least squares approach from the following equations:

i. Linear regression model

$a=\frac{1}{n} \sum_{i=1}^{n} P_{D i}$

$b=\sum_{i=1}^{n} P_{D i} X_{i} / \sum_{i=1}^{n} X_{i}^{2}$

Where, $\mathrm{n}$ is the number of historical data years.

ii. Exponential regression model

$a=\frac{1}{n} \sum_{i=1}^{n} Y_{i}$

$b=\sum_{i=1}^{n} Y_{I} X_{i} / \sum_{i=1}^{n} X_{i}^{2}$

Where, $Y_{i}=\operatorname{Ln} P_{D i}$

\subsubsection{Long-term load forecasting using modern techniques}

GA and PSO technique are used as modern techniques in this paper. They are employed to find the optimal values of the coefficients and exponents $(\mathrm{a}, \mathrm{b})$ in equations (1) and (2) that minimizes the absolute summation of the forecasting error (R) which can be obtained from equation (9) to get more accurate results of the load forecasting of the new city.

$R=P_{\text {Di,real value }}-P_{\text {Di,predicted }}$

Where, $\mathrm{P}_{\mathrm{Di}}$,real value is the existing recorded data. $\mathrm{P}_{\mathrm{Di} \text {,predicted }}$ is the type of the approximation used which is shown in equations (1) and (2). The fitness function for GA can be shown from the following equation [9]:

Fit $=1 /\left[1+k \sum_{i=1}^{n}|R|\right]$

Where, $\mathrm{k}$ is a scaling constant and can be taken as $(\mathrm{k}=0.0001)$. The fitness function for PSO technique can be used the same way as the objective function as shown in equation (9). The coefficients and exponents $(a, b)$, which are obtained using conventional technique, are used in these techniques to determine the range of the search space for each variable. The processes of GA and PSO technique for a certain problem to obtain the optimal solution are shown in Figs. (1) and (2) [8 - 10].

\subsection{Wind Farm Design}

After forecasting the peak load demand of the new city, the possible generations to feed the city can be determined. This city can be supplied from the conventional power generation or other sources of energy such as renewable energy sources or both. In this paper, the wind energy is used as a RES with conventional power generation (CPG) to feed this new city with energy requirements. An optimization of different WGMs can be obtained to determine the optimal WGM which is used to install wind farm at the installation site of the new city to be integrated with conventional power supply.

\subsubsection{Assessment of wind energy}

The available wind energy at any site can be assessed by studying the meteorological conditions at this site and the characteristics of the wind turbine and wind generator used. The wind speed recorded at the installation site must be transferred to the hub 


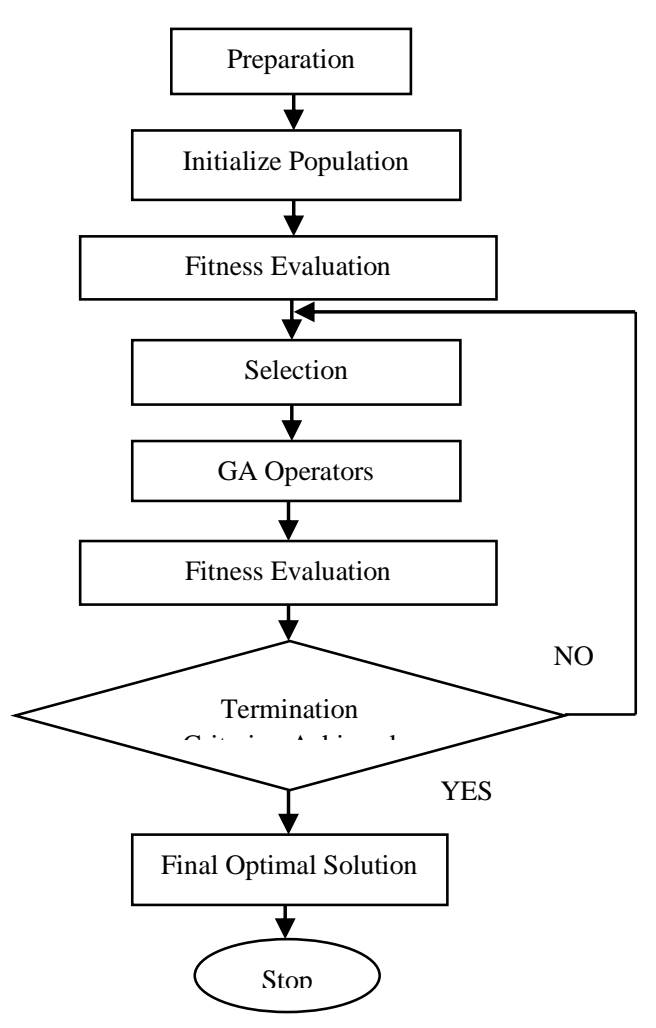

Fig. (1) Flow chart of GA

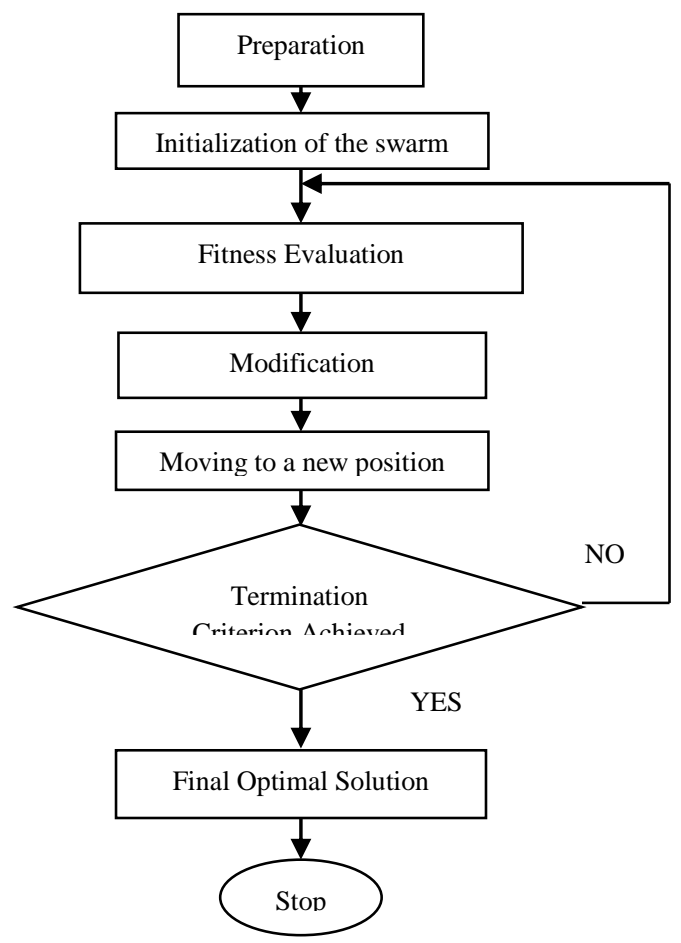

height of the wind turbine. The available wind speed at this height is given by the following equation [11]:

$V / V_{o}=\left(H / H_{o}\right)^{\alpha}$

Where, $\mathrm{V}$ is the wind speed at the hub height $\mathrm{H} . \mathrm{V}_{\mathrm{o}}$ is the wind speed at height $\mathrm{H}_{\mathrm{o}}$ (often a reference height a round of $10 \mathrm{~m}), \alpha$ is the ground surface friction coefficient. The mean wind speed $\left(\mathrm{V}_{\mathrm{m}}\right)$ over a period of time is obtained by the following equation [12, 13]:

$V_{m}=\frac{1}{n} \sum_{i=1}^{n} V_{i} \quad(m / s)$

Where, $V_{i}$ is the wind speed $(\mathrm{m} / \mathrm{s})$ at the ith observation time. $\mathrm{n}$ is the number of observations in the considered period. The variation in wind speed is best described by the Weibull probability distribution function (f) with two parameters, the shape parameter $\mathrm{k}$, and the scale parameter $\mathrm{c}[11,12$ and 13]. Where, $\mathrm{c}$ and $\mathrm{k}$ are deduced considering the wind speed at the installation site and given by the following equations [14]:

$$
\begin{aligned}
& k=0.254+0.315 * V_{m} \\
& c=1.1253 * V_{m}
\end{aligned}
$$

The characteristics of the WGM are rated power $\left(\mathrm{P}_{\mathrm{r}}\right)$, cut-in $\left(\mathrm{V}_{\mathrm{ci}}\right)$, rated $\left(\mathrm{V}_{\mathrm{r}}\right)$ and cut-out $\left(\mathrm{V}_{\mathrm{co}}\right)$ wind speeds. The average output power of this generator is given by the following equation [14]:

$P_{a v}=C . F * P_{r} \quad$ (watts)

Where, C.F is the capacity factor of wind generator and can be calculated from the following relation:

$$
\begin{aligned}
C . F= & {\left[\left[e^{\left[-\left(V_{c i} / c\right)^{k}\right]}-e^{\left[-\left(V_{r} / c\right)^{k}\right]}\right] /\left(\left(V_{r} / c\right)^{k}-\left(V_{c i} / c\right)^{k}\right)\right]-} \\
& e^{\left[-\left(V_{c o} / c\right)^{k}\right]}
\end{aligned}
$$

Therefore, the energy output of the WGM through the period $\mathrm{T}$ is given by the following equation:

$$
E_{W G}(T)=T * P_{a v} \quad(W h)
$$

\subsubsection{A comparison between different WGMs}

The generations of different WGMs for technical and economical sides are compared to deduce the optimal and most suitable WGM at the study installation site, as follows:

Fig. (2) Flow chart of PSO 


\section{i. Technical side study}

The technical side is introduced to compare between different WGMs at the installation site. It is stated here in terms of the generation per square meter of the area swept of the wind turbine $\left(\mathrm{A}_{\mathrm{T}}\right)$ as follows [15]:

$\sigma=E_{W G}(a) / A_{T}$

Where, $A_{T}$ is the swept area of wind turbine of the WGM. $E_{W G}$ (a) is the annual energy output of this generator.

\section{ii. Economical side study}

The economy of the wind generator is developed as a function of the capital cost of wind energy generation system used, the annual operation and maintenance costs as well as the unit energy cost of generated energy of this generation system. The capital cost of the wind generator (CC) is usually expressing in terms of its rated power or the swept area of its wind turbine as follows $[15,16]$ :

$C C=C_{T} * A_{T}=C_{W G} * P_{r}$

Where, $\mathrm{C}_{\mathrm{T}}$ is the cost per unit area of $\left(\mathrm{A}_{\mathrm{T}}\right) . \mathrm{C}_{\mathrm{WG}}$ is the cost per unit rated power of $\left(\mathrm{P}_{\mathrm{r}}\right)$.

The annual capital cost (ACC) is:

$A C C=D R * C C$

Where, DR is the annual discount rate which is given by the following relation [17]:

$D R=r(1+r)^{n} /\left[(1+r)^{n}-1\right]$

Where, $\mathrm{r}$ is the interest rate. $\mathrm{n}$ is the life-time of wind energy system. The annual operation and maintenance cost (AOC) is very small and can be represented as a percentage of the capital cost or as $\$ / \mathrm{kWh}$ of $\mathrm{E}_{\mathrm{WG}}$ (a). Thus, the total annual (TAC) and unit energy (UEC) costs are given as follows:

$T A C=A C C+A O C$

$U E C=T A C / E_{W G}(a)$

Therefore, different WGMs can be compared by using the value of UEC from economical side. Hence, after determining the optimal and most suitable WGM, it can be used to install the required wind farm at the study installation site.

\section{Applications}

This paper introduces an operation of wind energy as a RES with the main conventional generation to supply the new Borg El-Arab city with energy requirements. A forecasting of the load during different stages of constructing the new Borg El-Arab city is made to assess the capacity of the new city substation using extrapolation of trend curves as a conventional technique of load forecasting and GA and PSO technique as modern techniques of load forecasting. An optimization of different WGMs to install a large scale wind farm at the installation site of the new Borg El-Arab city to be integrated with conventional power supply is made.

\subsection{Long-Term Load Forecasting}

This study is carried out to verify the application of the conventional and modern techniques for load forecasting of new Borg El-Arab city. The extrapolation of trend curves method as a conventional technique and GA and PSO techniques as modern techniques with different regressions (linear and exponential) are applied for long-term load forecasting dependant on the historical data of the electrical peak load demand of new Borg El-Arab city, from year 2005 to year 2011, as shown in Table (1).

\subsubsection{Load forecasting using conventional technique}

Two approximations of extrapolation of trend curves are applied on this data to forecast the electrical peak load demand of new Borg El-Arab city.

Table (1) Electrical peak load data of new Borg ElArab city

\begin{tabular}{|c|c|}
\hline Year & $\mathrm{P}_{\mathrm{m}}(\mathrm{MW})$ \\
\hline 2005 & 151.2 \\
\hline 2006 & 164.7 \\
\hline 2007 & 177.3 \\
\hline 2008 & 188.1 \\
\hline 2009 & 200.7 \\
\hline 2010 & 211.5 \\
\hline 2011 & 220.5 \\
\hline
\end{tabular}




\section{i. Linear regression}

Load forecasting of the electrical peak load demand of new Borg El-Arab city can be obtained using equation (1) when linear regression model is used. The coefficients (a, b) in equation (1) can be determined using equations (3) and (4), depending on the historical data shown in Table (1). The coefficients $(\mathrm{a}, \mathrm{b})$ are equal to 187.714 and 11.604 , respectively. Fig. (3) shows the electrical peak load demand of new Borg El-Arab city from year 2012 to year 2035 using the linear regression model.

\section{ii. Exponential regression}

Also, load forecasting of the electrical peak load demand of new Borg El-Arab city can be obtained using equation (2) when exponential regression model is used. The exponents $(\mathrm{a}, \mathrm{b})$ in equation (2) can be determined using equations (5) and (6), depending on the historical data shown in Table (1). The exponents (a, b) are equal to 5.23 and 0.063 , respectively. Fig. (4) shows the electrical peak load demand of new Borg El-Arab city from year 2012 to year 2035 using the exponential regression model.

\subsubsection{Load forecasting using modern techniques}

GA and PSO technique are applied to estimate the parameters of linear and exponential regression models using the historical data shown in Table (1) to forecast the electrical peak load demand of new Borg El-Arab city. According to the values of the coefficients and exponents $(a, b)$, which are obtained using conventional technique, the range of the search space for both GA and PSO technique for $(a, b)$ using linear regression model is taken as 180:190 and $11: 12$, respectively, and using exponential regression model is taken as 4:6 and 0.01:0.1, respectively.

\section{i. Linear regression}

Load forecasting of the electrical peak load demand of new Borg El-Arab city can be obtained by estimating the values of the coefficients $(a, b)$ in the equation (1) as follows:

Applying the GA, the values of the coefficients (a, b) in the equation (1) are equal to 187.2221 and 11.9990 , respectively.

Applying the PSO, the values of the coefficients (a, b) in the equation (1) are equal to 187.7143 and 11.8391 , respectively.
The Figs. (5) and (6) show the electrical peak load demand of new Borg El-Arab city from year 2012 to year 2035 using the GA and PSO technique, respectively.

\section{ii. Exponential regression}

Load forecasting of the electrical peak load demand of new Borg El-Arab city can be obtained by estimating the values of the exponents $(a, b)$ in the equation (2) as follows:

Applying the GA, the values of the exponents (a, b) in the equation (2) are equal to 5.2272 and 0.0695 , respectively.

Applying the PSO, the values of the exponents (a, b) in the equation (2) are equal to 5.2271 and 0.0651 , respectively.

The Figs. (7) and (8) show the electrical peak load demand of new Borg El-Arab city from year 2012 to year 2035 using the GA and PSO technique, respectively.

\subsubsection{Choice of the best results for the load forecasting}

From the previous results, it can be found that the load forecasting results using the GA for exponential regression model has the best results compared to the other models. This is because the load forecasting results using this model are adapted on the actual peak load demand of the new Borg ElArab city from year 2012 to year 2015 as shown in Table (2).

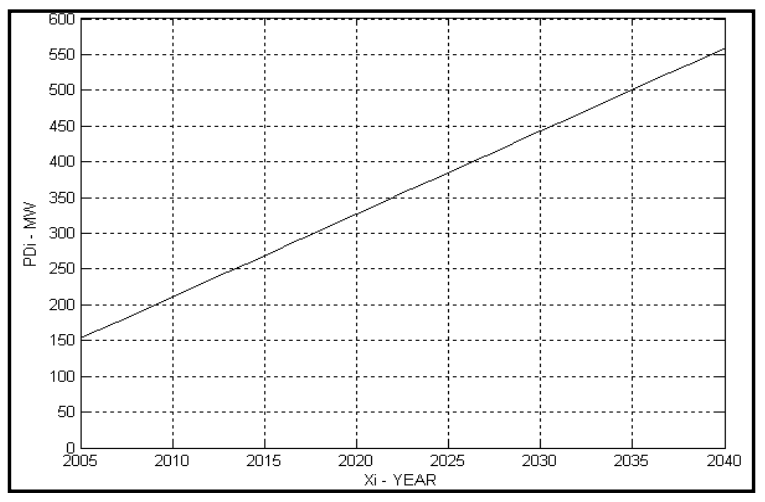

Fig. (3) Electrical peak load demand forecasted for new Borg El-Arab city using linear regression model 


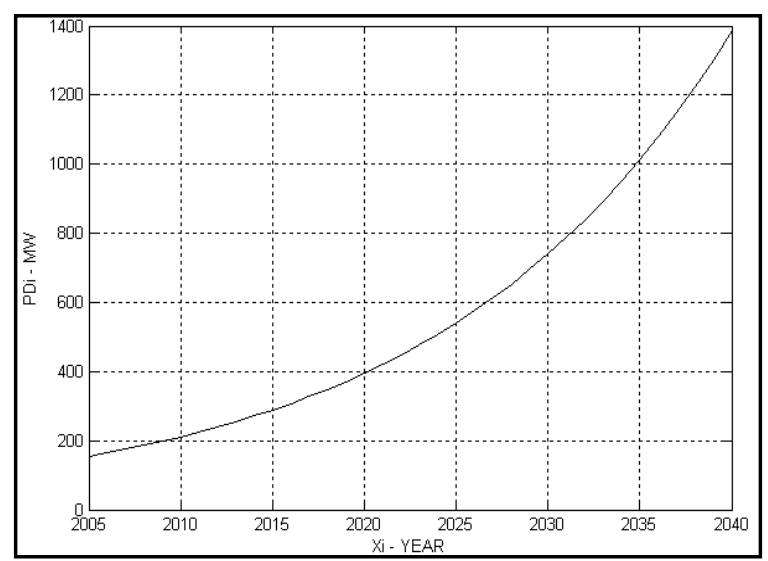

Fig. (4) Electrical peak load demand forecasted for new Borg El-Arab city using exponential regression model

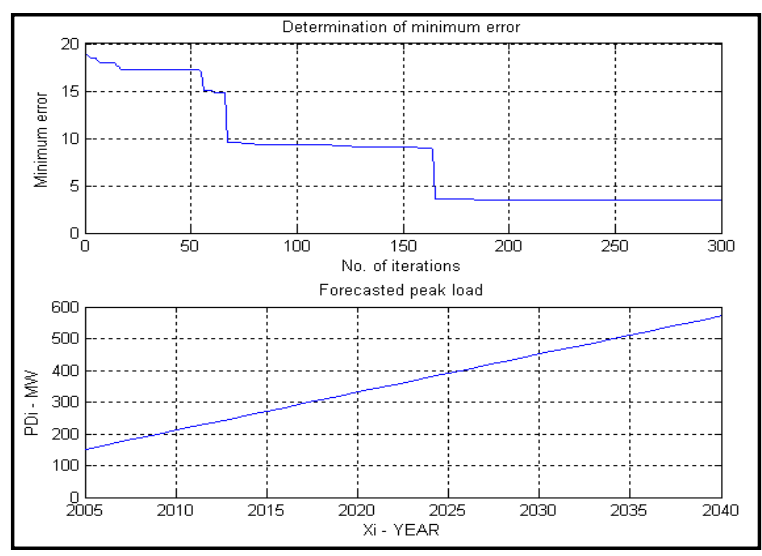

Fig. (5) Linear regression using GA

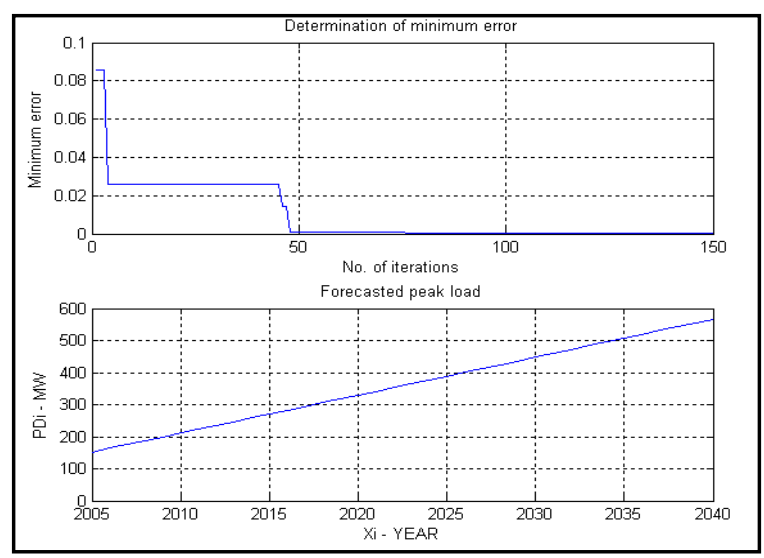

Fig. (6) Linear regression using PSO

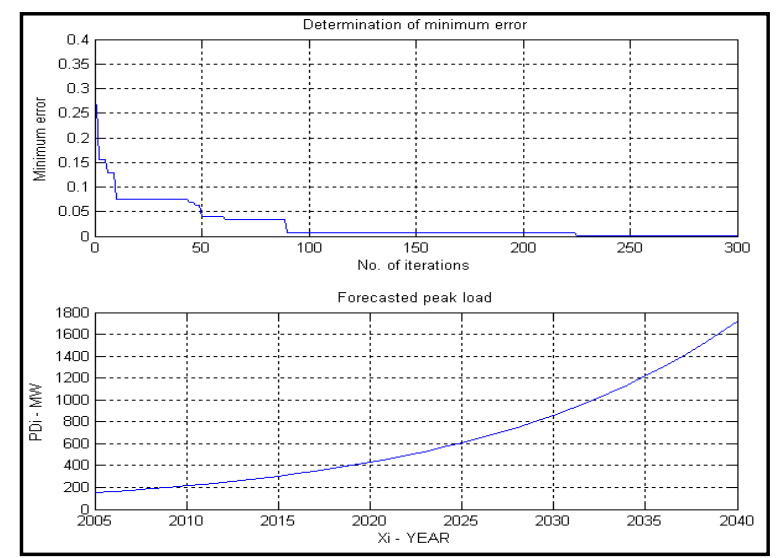

Fig. (7) Exponential regression using GA

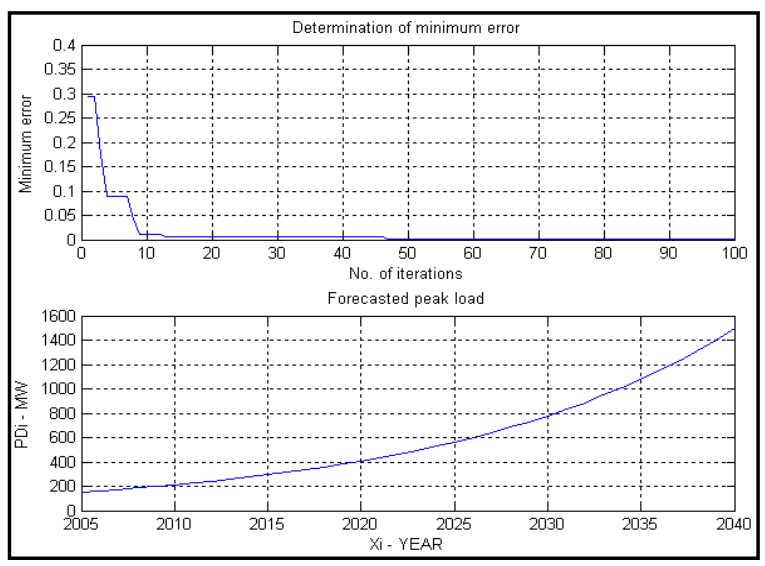

Fig. (8) Exponential regression using PSO

Table (2) Actual and forecasted peak load demand for new Borg El-Arab city from year 2012 to year 2015

\begin{tabular}{|c|c|c|c|c|}
\hline Year & 2012 & 2013 & 2014 & 2015 \\
\hline $\begin{array}{c}\text { Actual peak load demand, } \\
\text { MW }\end{array}$ & 244 & 261 & 280 & 299 \\
\hline $\begin{array}{c}\text { Forecasted peak load } \\
\text { demand, MW }\end{array}$ & 246 & 263.7 & 282.7 & 303 \\
\hline
\end{tabular}

\subsection{Wind Farm Design}

The wind energy of a number of WGMs is assessed and a comparison between them from technical and economical sides are made to obtain the optimal and most suitable WGM which will be used for designing a wind farm at New Borg El-Arab region on the Egyptian coast of the Mediterranean Sea. The chosen WGMs are taken with rated power of $1500,2500,3000$ and $3500 \mathrm{~kW}$. 


\subsubsection{Calculation of wind energy}

The recorded mean wind speeds at Borg ElArab region through a year, which are used to estimate the mean wind speeds at the altitudes of the study WGMs, are shown in Table (3) [18]. Fig. (9) gives the mean wind speed through a year at the altitudes of 1500, 2500, 3000 and $3500 \mathrm{~kW}$ WGMs at Borg El-Arab site. The mean wind speed $\left(\mathrm{V}_{\mathrm{m}}\right)$ at the considered site is used to develop Weibull parameters (shape $\mathrm{k}$ and scale $\mathrm{c}$ parameters) for the wind speed through a year. The parameters $\mathrm{c}$ and $\mathrm{k}$ can be used with the characteristics of the different WGMs as showing in Table (4) [19 - 22] to estimate the monthly capacity factor, generation and the annual generation of the WGMs at the study installation site, which are given in Table (5). Fig. (10) illustrates the monthly average power generation of the WGMs.

\subsubsection{A comparison between different WGMs}

Now, the WGMs can be compared from technical and economical sides to choose the optimal and most suitable WGM which will be used in wind farm design at Borg El-Arab site. From Table (5), the annual generation of the WGMs can be used to compare between the different WGMs from technical side as shown in Fig. (11). From this Figure, it can be concluded that the $3000 \mathrm{~kW}$ WGM is the optimal one compared to 1500,2500 and $3500 \mathrm{~kW}$ WGMs at Borg El-Arab site from technical side. Also, the economical side study is applied to compare between the WGMs at Borg El-Arab site. It can be assumed that the capital cost is $340 \$ / \mathrm{m}^{2}$ of $\mathrm{A}_{\mathrm{T}}$, the annual operation and maintenance cost is $1.0 \phi / \mathrm{kWh}$ of $\mathrm{E}_{\mathrm{WG}}$ (a) and the interest rate and life time are $10 \%$ and 25 years, respectively during carrying out of these applications. Fig. (12) shows the result of this study where the $3000 \mathrm{~kW}$ WGM is the optimal one compared to 1500,2500 and $3500 \mathrm{~kW}$ WGMs at Borg El-Arab site from economical side.

\subsubsection{Optimal design of Borg El-Arab wind farm}

According to the general considerations of wind farm design, the optimal distance between the rows is equal to 7 rotor diameters and the optimal distance between the turbines in the same row is equal to 4 rotor diameters [11]. The chosen site area at Borg El-Arab region is $544.882 \mathrm{~km}^{2}$ [23]. The number of wind turbines is determined according to the site area, the optimal spacing between the rows and the turbines in the same row as well as the forecasted peak load demand of the new Borg El-
Arab city which has been obtained in the previous section. Fig. (13) shows the design configuration of the wind farm and its dimensions at the installation site.

Table (3) Mean wind speed through a year at Borg El-Arab region

\begin{tabular}{|c|c|}
\hline Month & $\mathrm{V}_{\mathrm{m}}(\mathrm{m} / \mathrm{s})$ \\
\hline Jan & 4.63 \\
\hline Feb & 5.14 \\
\hline Mar & 5.66 \\
\hline Apr & 5.66 \\
\hline May & 6.17 \\
\hline Jun & 6.17 \\
\hline Jul & 6.17 \\
\hline Aug & 6.17 \\
\hline Sep & 5.66 \\
\hline Oct & 5.66 \\
\hline Nov & 5.14 \\
\hline Dec & 4.63 \\
\hline
\end{tabular}

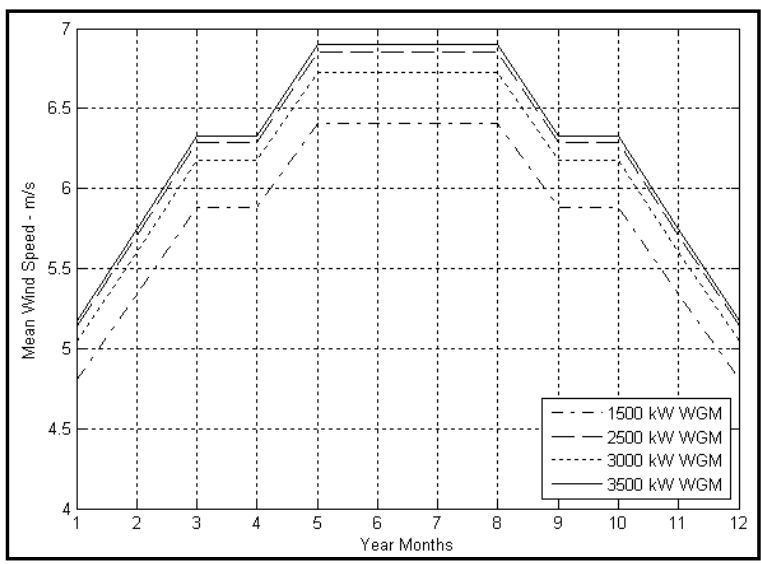

Fig. (9) Mean wind speed at the altitudes of the WGMs through a year at Borg El-Arab site

Table (4) Characteristics of the different WGMs

\begin{tabular}{|c|c|c|c|c|}
\hline WGM Variable & $\begin{array}{c}\mathrm{P}_{\mathrm{r}} \\
(\mathrm{Kw})\end{array}$ & $\begin{array}{c}\mathrm{V}_{\mathrm{ci}} \\
(\mathrm{m} / \mathrm{s})\end{array}$ & $\begin{array}{c}\mathrm{V}_{\mathrm{r}} \\
(\mathrm{m} / \mathrm{s})\end{array}$ & $\begin{array}{c}\mathrm{V}_{\mathrm{co}} \\
(\mathrm{m} / \mathrm{s})\end{array}$ \\
\hline $1500 \mathrm{~kW}$ & 1500 & 3 & 12 & 25 \\
\hline $2500 \mathrm{~kW}$ & 2500 & 3 & 14 & 25 \\
\hline $3000 \mathrm{~kW}$ & 3000 & 4 & 12 & 25 \\
\hline $3500 \mathrm{~kW}$ & 3500 & 3 & 13 & 25 \\
\hline
\end{tabular}


Table (5) Monthly generation $\left(\mathrm{E}_{\mathrm{WG}}\right)$ and annual generation $\left(\mathrm{E}_{\mathrm{WG}}\right)$ of the WGMs at Borg El-Arab site

\begin{tabular}{|c|c|c|c|c|}
\hline WGM & $1500 \mathrm{~kW}$ & $2500 \mathrm{~kW}$ & $3000 \mathrm{~kW}$ & $3500 \mathrm{~kW}$ \\
\cline { 2 - 5 } & $\begin{array}{c}\mathrm{E}_{\mathrm{WG}} * 10^{5} \\
(\mathrm{kWh})\end{array}$ & $\begin{array}{c}\mathrm{E}_{\mathrm{WG}} * 10^{5} \\
(\mathrm{kWh})\end{array}$ & $\begin{array}{c}\mathrm{E}_{\mathrm{WG}} * 10^{5} \\
(\mathrm{kWh})\end{array}$ & $\begin{array}{c}\mathrm{E}_{\mathrm{WG}} * 10^{5} \\
(\mathrm{kWh})\end{array}$ \\
\hline January & 2.0497 & 2.7896 & 3.7143 & 4.5315 \\
\hline February & 2.1225 & 2.8508 & 3.9852 & 4.6787 \\
\hline March & 2.6857 & 3.567 & 5.2093 & 5.9108 \\
\hline April & 2.5991 & 3.4519 & 5.0413 & 5.7201 \\
\hline May & 3.0468 & 4.015 & 6.0749 & 6.7079 \\
\hline June & 2.9485 & 3.8855 & 5.8789 & 6.4915 \\
\hline July & 3.0468 & 4.015 & 6.0749 & 6.7079 \\
\hline August & 3.0468 & 4.015 & 6.0749 & 6.7079 \\
\hline September & 2.5991 & 3.4519 & 5.0413 & 5.7201 \\
\hline October & 2.6857 & 3.567 & 5.2093 & 5.9108 \\
\hline November & 2.2742 & 3.0545 & 4.2699 & 5.0129 \\
\hline December & 2.0497 & 2.7896 & 3.7143 & 4.5315 \\
\hline Annual & 31.155 & 41.453 & 60.289 & 68.632 \\
\hline
\end{tabular}

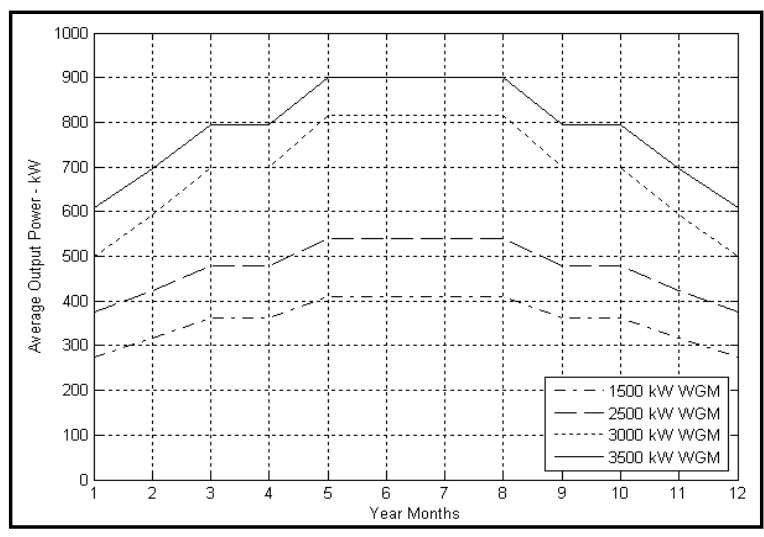

Fig. (10) Power generation at the altitudes of the WGMs through a year at Borg El-Arab site

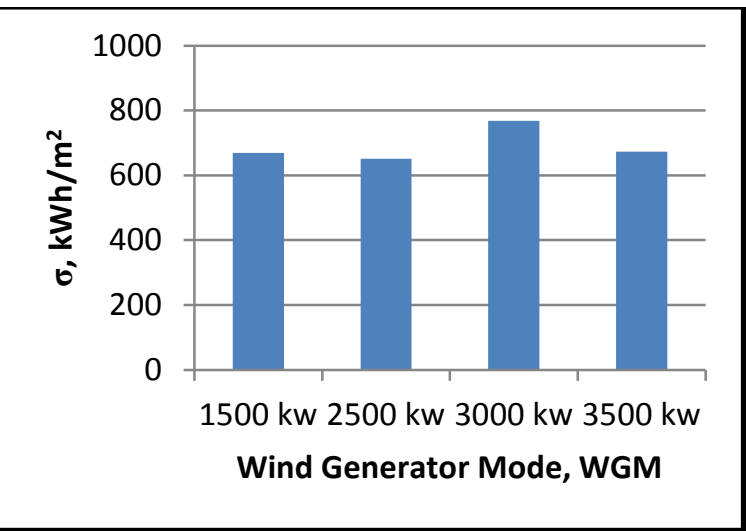

Fig. (11) A comparison between the different WGMs related to technical side at Borg El-Arab site

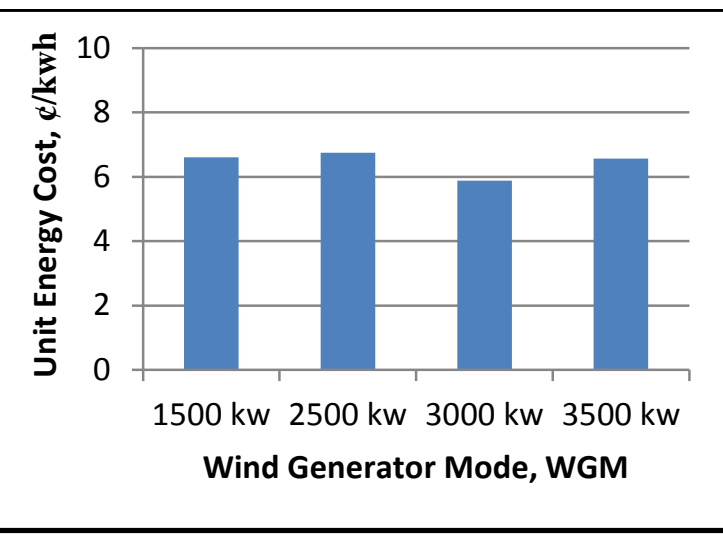

Fig. (12) Unit Energy Cost (UEC) of the WGMs installed at Borg El-Arab site

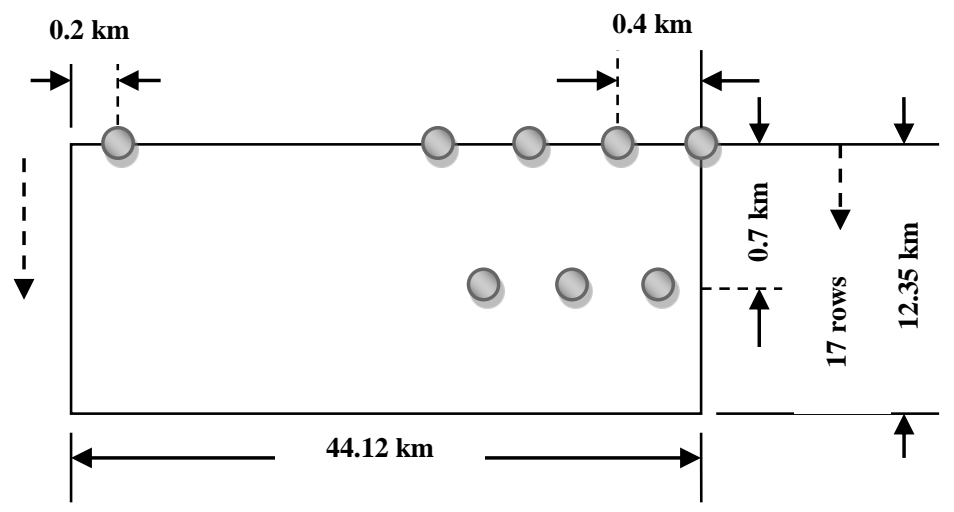

Fig. (13) Configuration of the designed wind farm at the installation site [23]

From this Figure, it can be found that:

The number of rows at the wind farm $\left(\mathrm{N}_{\mathrm{R}}\right)=$ $\frac{12.35}{0.7}=17.65 \cong 17$

The number of turbines per row $\left(\mathrm{N}_{\mathrm{TR}}\right)=$ $\frac{44.12-0.2}{0.4}=109.8 \cong 109$

The number of turbines in the wind farm $\left(\mathrm{N}_{\mathrm{T}}\right)=$ $\mathrm{N}_{\mathrm{R}} * \mathrm{~N}_{\mathrm{TR}}=17 * 109=1853$

The average output power from $3000 \mathrm{~kW}$ WGM is equal to $681.163 \mathrm{~kW}$. Then, the power available from the farm can be obtained from the following equation:

Power available from the farm = $\mathrm{P}_{\mathrm{av}}$ (of one turbine) $* \mathrm{~N}_{\mathrm{T}}=681.163 * 1853=$ $1262195.039 \mathrm{~kW}=1262.195 \mathrm{MW}$. 


\section{Conclusions}

In this paper, the possibility of operating RESs with the main conventional supply (substation) to supply new cities with energy requirements has been discussed. From this study, the following conclusions have been deduced:

The load forecasting during different stages of constructing the new city has been made to assess the generation capacity of the new city. Long-term load forecasting has been presented to know the peak load demand development of new Borg El-Arab city up to year 2035. Extrapolation of trend curves technique has been applied as a conventional technique and GA and PSO technique have been applied as modern techniques to obtain more accurate results for load forecasting. The electrical peak load demand forecasted of new Borg El-Arab city is increased by variable and fast increasing rate. However, this result agrees with the nature of the electrical peak load demand development in new Borg El-Arab city which will be one of the important industrial cities in Egypt in the near future.

A comparison between different WGMs have a rated power of 1500, 2500, 3000 and $3500 \mathrm{~kW}$ has been obtained from technical and economical sides which helps to deduce the optimal and most suitable WGM which will be used for designing the wind farm in Borg El-Arab region beside the conventional power generation system.

However, $3000 \mathrm{~kW}$ WGM is the optimal and most suitable one which has been used for designing the wind farm. It has been found that the wind farm power of $3000 \mathrm{~kW}$ WGM is enough for completely feeding new Borg El-Arab city up to year 2035. This means that the supplied power from the conventional power generation which feeds the city will be minimized. Also, the electrical network is fed from the surplus of wind power at minimum load periods of the city up to year 2035 .

\section{References}

[1] J. Bebic, "Power System Planning: Emerging Practices Suitable for Evaluating the Impact of High-Penetration Photovoltaics", Report, National Renewable Energy Laboratory, Available online at http://www.osti.gov/bridge, 2008.

[2] B. Ul Islam, "Comparison of Conventional and Modern Load Forecasting Techniques Based on Artificial Intelligence and Expert System", Vol. 8, No. 3, pp. 504 - 513, International Journal of Computer Science Issues (IJSCI), 2011.

[3] R. Wiser and Z. Yang, "Wind Energy", Chapter, Available online at http://www.ipcc.ch/pdf/special-reports/srren /Chapter7WindEnergy.pdf.

[4] "Wind Energy Benefits", Sheet, Wind Powering America, Available online at http://www.windpoweringamerica.gov.

[5] A. Abou El-Ela, A. El-Zeftawy, S. Allam, and G. Atta, "An Optimization Planning Technique for Suez Canal Network in Egypt", Vol. 80, pp. 196 - 203, International Journal of Electric Power Systems Research (EPSR), 2010.

[6] X. Wang and J. Macdonald, "Modern Power System Planning", Book, McGraw-hill international Book Company (UK) limited, 1994.

[7] R. Sullivan, "Power System Planning", Book, McGraw-Hill International Book Company, New York, 1977.

[8] A. Abou El-Ela, S. Allam, and M. Shatla, "Maximal Optimal Benefits of Distributed Generation Using Genetic Algorithms", Vol. 80, pp. 869 - 877, International Journal of Electric Power Systems Research (EPSR), 2010.

[9] Kh. El-Naggar and Kh. Al-Rumaih, "Electric Load Forecasting Using Genetic Based Algorithm, Optimal Filter Estimator and Least Error Squares Technique: Comparative Study", Vol. 6, pp. 728 - 732, World Academy of Science, Engineering and Technology, 2007.

[10] D. Rini, S. Shamsuddin and S. Yuhaniz, "Particle Swarm Optimization: Technique, System and Challenges", Vol. 14, No. 1, pp. 19 
- 27, International Journal of Computer Applications (0975 - 8887), 2011.

[11] G. Masters, "Renewable and Efficient Electric Power Systems", Book, Wiley-Interscience, John Wiley \& Sons, Inc., Publication, Hoboken, New Jersey, 2004.

[12] S. Mathew, "Wind Energy: Fundamentals, Resource Analysis and Economics", Book, Springer-Verlag Berlin Heidelberg, the Netherlands, 2006.

[13] M. Patel, "Wind and Solar Power Systems", Book, U.S. Merchant Marine Academy Kings Point, CRC Press, New York, 1999.

[14] A. EL-Zeftawy, S. Allam and N. Shehata, "Optimizing and Dispersed Wind Generators on Power System with Application in Egypt", $10^{\text {th }}$ World Wind Energy Conference \& Renewable Energy Exhibition in Cairo, Egypt, 2011.

[15] S. Allam, A. EL-Zeftawy and A. Doso, "Assessment of Operating Wind Energy Generation System to Supply Isolated Loads with Applications in Egypt", Paper ID 204, $14^{\text {th }}$ International Middle East Power Systems Conference (MEPCON'10), Cairo University, Egypt, 2010.
[16] A. Gado, H. Okasha and G. Salama, "Optimizing Alternative Backup Power Supplies with Wind Generator to Supply Isolated Loads", No. 0233, 22 ${ }^{\text {nd }}$ International Conference on Electricity Distribution, CIRED, Stockholm, 2013.

[17] G. Ali and A. EL-Zeftawy, "Correlation between Renewable Energy Source's Energy Output and Load", Vol. 28, pp. $513-521,5^{\text {th }}$ International Conference on Energy and Environment, Cairo, Egypt, 1996.

[18] "Wind \& weather statistics Borg El-Arab Airport", www.windfinder.com.

[19] "1500 kw Wind Turbine Generator", Data Sheet, http://au.alibaba.com.

[20] "Product Data Sheet N90/2500 (2.5 MW)", Data Sheet, www.nordex-online.com.

[21] "General data about Acciona AW3000-100 wind turbine", Data Sheet, www.thewindpower.net.

[22] "General data about e.n.o. energy 114 wind turbines", Data Sheet, www.thewindpower.net.

[23] "Borg El-Arab Region Map", Google Maps, http://maps.google.com. 